ISSN 1991-8631

Original Paper

http://indexmedicus.afro.who.int

\title{
Some limitations in healthcare services in Dschang, West Region, Cameroon
}

\author{
Catherine N. K. FUSI NGWA*, Vincent K. PAYNE and Chrysanthus NCHANG \\ Department of Animal Biology, Faculty of Science, University of Dschang, P.O. Box 67 Dschang, Cameroon. \\ *Corresponding author, E-mail: fncathkesah@yahoo.com
}

\begin{abstract}
Successful scaling up of health services in any locality requires knowledge about extant resources, constraints in health policy implementation and delivery of interventions, achievable through biomedical research, thus, this study. Health systems in Dschang, and primary care delivery in three hospitals viz the Dschang District Hospital, the Adlucem Medical Foundation and the "Hôpital Saint Vincent de Paul," were assessed from September 2007 to April 2008, through interviews and administration of structured questionnaires to heads, personnel and patients, including researchers' observations. Ambulatory services, nursing and residential care facilities, many allied health professions, intensive care units, hospital infection surveillance and control programs, and informatics were notably absent. Poor hospital reforms led to severe implications particularly for end users. Records carry important information and provide a source of epidemiological data for surveillance systems but personnel were negligent about them. Understaffing, lateness, absenteeism and unawareness resulted in incomplete tasks. Lack of training and incentives, loss of privileges, ethical misconduct, tribal loyalty, socio-cultural and religious barriers, and stigma led to apathy and/or laxity. Cleaners were not well paid nor equipped for their jobs, and where they were non-existent, staff who of course were not motivated, limited cleaning to the wards, leaving out yards and the greater environment littered by wastes. Improving medical and diagnostic services, ferocious attention to nursing and hygiene care, barrier precautions, effective antibiotic formularies, adequate waste disposal and refresher courses to create or enhance awareness were prioritized from May 2009. Hospital administration had to work in synergy with staff and patients to overcome loopholes and scams in healthcare delivery. In the face of global economic down turn, cost efficiency and services boost especially consultations at regional levels should ensure equitable access to health services in the country. The introduction of telephone and computerized bookings for appointments, medical secretaries, receptionists, healthcare assistants and epidemiologists were recommended for consideration.
\end{abstract}

(C) 2013 International Formulae Group. All rights reserved.

Keywords: Health systems, personnel, patients, primary care delivery, barriers, mitigation

\section{INTRODUCTION}

Healthcare involves the diagnosis, treatment and prevention of disease, illness, injury, and other physical and mental impairments in humans. It encompasses primary, secondary and tertiary services including public health. Primary care delivery covers the widest scope of care to communities within a healthcare system-an organization set up to meet the health needs of target populations. Secondary care involves specialized hospital patient care, whereas tertiary care is specialized consultative 
healthcare for inpatients. Quaternary care is a highly specialized extension of tertiary care dealing with experimental medicine and some types of uncommon diagnostic or surgical procedures. Public health (community and home care) delivers interventions outside of health facilities including professional services rendered in residential and community settings in support of self-care, home care, long term care, assisted living, treatment for substance use disorders and other types of health and social care services (Braithwaite et al., 2013; Evans et al., 2013; Gomez-Batiste et al., 2013; Girot, 2013). The quantity and quality of many healthcare interventions are improved through biomedical and pharmaceutical research which forms the basis of evidence-based medicine, practice and policy in health systems (Wikipedia, 2013a; 2013b).

Health is wealth. Thus, the health of a population is of utmost importance to the socio-economic, cultural and political development of any nation. In Cameroon, the health system is organized at three levels: the lowest comprises health centres to cater for the health of rural populations with limited services; the second consists of district hospitals with general medical services; and the highest level accommodates central and regional hospitals with various medical specialties. According to the World Health Organization (WHO, 2012), a wellfunctioning health care system requires a robust financing mechanism; a well-trained and adequately-paid workforce; reliable information on which to base decisions and policies; and well maintained facilities and logistics to deliver quality medicines and technologies.

This investigation stemmed from concerns that healthcare in Dschang leaves much to be desired. Public, community and private health systems, and primary care delivery, in Dschang and its environs were scrutinized. The objective was to expose lapses in patient care, information crucial in policy planning and amelioration of the health situation of the community.

\section{MATERIALS AND METHODS}

Geographical location, climate and vegetation of the study region

Dschang is located between latitude $05^{\circ} 20^{\prime} \mathrm{N}$, longitude $10^{\circ} 03^{\prime} \mathrm{E}$, and having an altitude of $1382-1500 \mathrm{~m}$. The climate is Sudano-Guinean with two characteristic seasons-dry season which runs from midnovember to mid-march, and a rainy season which runs from mid-march to mid-november. Dschang has an annual precipitation range of $1313 \mathrm{~mm}$ to $2288 \mathrm{~mm}$, with a relative humidity of $76.8 \%$, and an annual sunshine of 1873 hours, with an average daily temperature of $20{ }^{\circ} \mathrm{C}$ (Mpoame and Essomba, 2000). The vegetation is grassland savannah, interspersed with few trees of various types. There are a few slow flowing streams that meander around the town and one, which is fast flowing forming a waterfall. There is a municipal lake, which is in Foto/Keleng, people live very close to this lake. The soils are the ferrallitic type. The natives are of the Bamileke ethnic group with the main religious groups being Christians and Moslems. The principal occupation is business and subsistence farming but the majorities of youths are students or pupils (Mpoame and Essomba, 2000).

\section{Setting}

The Dschang District Hospital (DDH), the Adlucem Medical Foundation Hospital (AH) and the "Hôpital Saint Vincent de Paul" (HSVP) in Dschang, West Region, Cameroon, the major health centres in the Dschang municipality.

\section{Ethical clearance (Declaration of Helsinki)}

Authorization to carry out this study was obtained from the Chief Medical Officers of the various hospitals. Informed verbal consent was obtained from staff and patients who took part in interviewers and completion of structured questionnaires.

\section{General description of the study hospitals}

The DDH went operational in 1957. It is located above the bilingual primary school, 
opposite the Dschang University entrance and lies on latitude $10^{\circ} 03^{\prime} 724^{\prime \prime}$, longitude $5^{\circ} 26^{\prime} 843^{\prime \prime}$ and an altitude of $1391 \mathrm{~m}$. It has a capacity of 200 beds with a team of 5 doctors, 45 nurses and 6 laboratory workers. The $\mathrm{AH}$ was created in 2003 and is located at Ngui quarter in Dschang. It lies on latitude $10^{\circ} 26^{\prime} 251^{\prime \prime}$, at an altitude of $1343 \mathrm{~m}$. It has a capacity of 37 beds, with a staff of 18,1 doctor, 2 laboratory workers and 15 nurses. The HSVP transformed from a dispensary to a full hospital in 2003. It is situated at "Grande Mission" quarter of the road to Fongo Tongo. It lies on latitude $10^{\circ} 02^{\prime} 814^{\prime \prime}$, longitude $5^{\circ} 27^{\prime} 475^{\prime \prime}$ and an altitude of $1422 \mathrm{~m}$. It has a capacity of 110 beds, 4 medical doctors, 40 nurses, 7 laboratory workers, 1 administrator and 1 assistant administrator.

\section{Pre-study contact}

The authorities of health centres and hospitals in Dschang were contacted and interviewed about health services rendered to the public, and then the aim of this study explained to them. Letters seeking the authorization to grant permission were presented to the directors of the three hospitals who consented to partake in this study, and were duly accepted and signed by them. Subsequent visits for the administration of questionnaires and interviews were arranged with the general supervisors and/or nurse heads of the various specialties after obtaining informed consent.

\section{Administration of questionnaires/ interviews}

In the three study hospitals, information on work related problems was sought from 35 workers (doctors, nurses, laboratory workers, administrative staff, cleaners and one mortuary attendant at the DDH). Information sought included: the need to control infection, predisposing factors of communicable diseases in the hospital setting, availability of care facilities or materials, drug therapy, general behaviour in the hospital, decontamination and wastes disposal. Personnel were equally interrogated on aspects related to working conditions, provision of basic amenities-light, water, bathrooms, appropriate lavatory facilities, cafeteria or canteens and job satisfaction. Factors which influence disease transmission or other factors which impact on healthcare in hospitals such as overcrowding, bed spacing, isolation and staff-to-patient ratio were examined including personal observations of the researchers. Oral interviews were granted to patients (100) about care rendered to them, degree of satisfaction and their relationship with hospital workers.

\section{Difficulties}

This study was carried out from one unit to the other in the various institutions. At the DDH, it was possible to meet most of the personnel to whom questionnaires were distributed in the various units. However, some of the nurses misplaced their copies and despite several replacements, some could not still be retrieved. Some other nurses deliberately refused to cooperate despite repeated explanations of the importance of this exercise. A total coverage in all the units of the AH and HSVP was not possible due to their inaccessibility. In these hospitals, the general supervisors who happened to be quite detached from the hospital care services still had to endorse reception in the various hospital units for the administration of questionnaires despite the fact that permission had been granted by the medical officers for the work to be done. This also prevented the researchers from studying the bed occupancy rate in the hospitals during the study period and getting in contact with as many patients as possible. This attitude exhibited by the supervisors was time consuming, at times due to either lateness or absenteeism from work. In other instances, only the nurse heads of units completed the questionnaires and repeated attempts to persuade them to allow access to other personnel under them were 
futile. They claimed that they represented their subordinates and supplied sufficient information requested for. Consequently only 35 staff completed questionnaires for the study and only 100 patients were interviewed. Attempts at including some private healthcare institutions which offered similar services were unsuccessful because the chief medical officers did not permit the work.

\section{RESULTS}

\section{General practices}

The health system in Dschang was observed to offer general in-patient and outpatient health services in medicine, dentistry, nursing and pharmacy, with the allied health professions not well defined and utilized. Gynaecology, ophthalmology and transplant surgery were also offered. Notably absent were ambulatory health services, nursing and residential care facilities; intensive care units (ICUs), receptionists, medical secretaries, epidemiologists, and telephone and computerized bookings for appointments within health facilities. Diagnostic laboratories were poorly equipped, in some cases manned by insufficient staff, with no resources to perform most basic laboratory procedures. The declining economy left hospitals with limited resources to cover all basic health services. In the three study hospitals, there were no records departments and no record storage facilities. At the DDH and the $\mathrm{AH}$, many records were observed to be destroyed by water, rats and insects (cockroaches and woodlice), while those of the HSVP were well sectioned in a statistics room.

From the questionnaires administered, staff believed that the control of infectious diseases was necessary because it would facilitate the putting in place of measures that will limit the propagation of microbes and avoid intra-hospital contamination. Infection diagnosis was based on clinical presentations, and drug prescription predicated on formularies not tested in vitro, thus, broad spectrum antibiotics were mostly prescribed.
Generally, culture and antibiotic testing were out of reach of patients in the study locality, and such tests were not subsidized by the government. Today, the DDH in particular has been renovated, so many programs in the pipeline including culture and antimicrobial susceptibility testing. At the "Hopital Saint Vincent de Paul", culture and sensitivity testing commenced in earnest in 2011.

Incessant cuts of pipe-borne water and electricity at the $\mathrm{DDH}$ and the $\mathrm{AH}$ lend to poor personal and environmental hygiene, use of contaminated water (due to seepage from nearby pit toilets) from springs, and at times from wells and streams to bath and launder, and disruption of the smooth functioning of various departments particularly the laboratory, theatre and reanimation. To ensure the continuous presence of water, HCPs stored water in recipients for use when municipal supplies were interrupted. However, water was stored for a long time in some instances without replacing. At the DDH, most staff believed that cleaning schemes were not satisfactory and waste was not properly disposed of. Dirt dropped off bins on the way to the incinerator. Unfortunately, this road was used by school children who picked up and played with dangerous wastes such as used syringes and catheters which were sources of cross contamination. Less than $50 \%$ of workers received necessary vaccines (against hepatitis $\mathrm{B}$, tetanus, meningitis and poliomyelitis). Also, at the $\mathrm{DDH}$, regular gatherings of medical staff in the hospital were reportedly suspended because personnel used these forums to lay their grievances and to demand for better working conditions. The hospital environment was hardly cleaned (as the hospital had no cleaners), littering with dirt. In fact, drops of blood from accident victims were seen dried on corridors for several weeks. Nurses apart from rendering healthcare to patients, had the duty of cleaning hospital wards (once a week in the surgical unit, twice a week in the general wards, and every morning in the Paediatric unit). Lavatories and hospital walls were 
dilapidated. However, from May 2009, services and facilities were overhauled, cleaners recruited, staff meetings and many incentives re-introduced to motivate staff.

The entire Adlucem hospital was cleaned every day, except on weekends (Saturdays and Sundays). The cleaner confirmed the presence of basic cleaning materials, but complained of long working hours and low wages, thus expressing the need for hospitals to engage more cleaners. Waste disposal was done daily, but it was important to get a new site because the current one was full and waste needed treatment before disposal so that it did not pose hazards to the population.

At the "Hôpital Saint Vincent de Paul," personnel revealed that some patients were usually absent from hospital wards as they went to consult witchdoctors. This was quite evident as some declarations were seen in patient records as caretakers signed engagements indicating that they were taking their patients to traditional doctors. However, when patients' resorted to gross indiscipline, they were expelled. The hospital had a team of cleaners (9), with cleaning schedules respected. Working materials were always available, but cleaners expressed the need for these materials to be replaced regularly. The cleaners also complained of long working hours and low wages, and proposed that complete hand gloves and face shield be provided by hospital authorities. They equally expressed the need for small-sized bins to be provided in the wards and two dust bins per service to separate hospital waste from patients' wastes.

In the study hospitals, some other limiting factors that hampered healthcare delivery included: lack of adequate patient care materials such as cotton wool, sterilizers, thermometers; and patient taboos (cultural myths such as the administration of healthcare to some notables by particular HCPs). Also observed were dilapidated infrastructure and equipment, non-usage of mosquito nets and insecticides for vector control, poor drainage of culverts (standing water noticed), lawns not mown, malnutrition, poor diet, drug abuse (misuse i.e. not respecting medication intervals, under-use, overuse and some staff selling drugs of unknown quality or origin to patients), no surveillance system in place to document disease burden and plausible preventive strategies, no trained staff to conduct surveillance and raise awareness and improper waste disposal. To ameliorate the situation, HCPs proposed that hospitals should be renovated, beds as well as mattresses changed, continuous formation/teaching of personnel, personnel regularly vaccinated, hospital beds terminally disinfected before the installation of new arrivals and the entire hospital well electrified. Finally staff should be updated on recent healthcare techniques through the installation of computers which will enable intranet and internet services in the hospital, communiqués, posters and refresher courses. Understaffing was a problem in these hospitals. At times only one nurse stayed on guard (per up to 30 beds) in a unit. Nurses have been trained but not recruited; some aging ones are either dead or retired and have not been replaced. Where one nurse stays on guard, in times of emergency, may ignore aseptic procedures giving room for more infections.

Through interrogations, HCPs revealed that some patients refused hospitalisation despite the severity of their conditions because they could not afford for laboratory tests, bed fees and cost of treatment. Others spent several days in hospital without undergoing laboratory tests until when they eventually left. Other patients believed their conditions were a result of some ancestral curse and preferred witchdoctors whom they believe would relieve them of their ailments. They did not consider the hospital capable of healing them, reason why some patients in critical conditions when admitted, discontinued treatment once they gained consciousness. Other patients when slightly 
relieved failed to take their drugs regularly. Due to hardship, large numbers of patients left the hospital against medical advice, on the pretext, they were going for external treatment, but once they left, it was difficult to verify if they continued. Others were expected to report for re-examination but compliance was low.

The mortuary attendant at the DDH revealed that despite all attempts, it had been impossible to prevent relations from getting close contact with corpses, especially when over grieved after losing loved ones. This was even more compounded by the fact that in the Bamileke setting, once at home, corpses might be operated upon for local autopsy rituals in order to ascertain the cause of death. On its part, the hospital did not furnish the necessary working materials such as protective apparels, despite the risky nature of the job. The attendant had to engage people to fetch water indispensable for the functioning of the mortuary, as it had been cut off municipal supplies for a long time. However, electric interruptions did not affect the mortuary as it had a standby generator but in some occasions was fuelled by the attendant. The main problem encountered by the attendant was the public who thought they were extorted. Meanwhile, products for the treatment of corpses such as formol that is toxic and thus risky, and other materials for the general upkeep of the mortuary were not supplied by the hospital, such that the public had to be charged more to cover costs. Another problem raised was the small capacity of the mortuary which at times could not accommodate all incoming corpses but which has now been expanded. Finally, the attendant believed that better services could be rendered if the following were put at the disposal of the mortuary: a minibus to run the services, mobile telephones with communication credit, a constant supply of water, increase in the size of the mortuary, free and regular vaccinations of personnel, chapels for religious services and a hall to accommodate the waiting crowd during the preparation of corpses for withdrawal, most of these have also been provided.

\section{Other hospital/patient practices}

HCPs reported that some patients or their caretakers sometimes imposed the type of treatment they wanted and either refused or pulled off intravenous drips, and refused to take particular drugs prescribed. Some mothers objected the use of syringes on their children opting for alternative forms of drug administration. Others moved about in the hospital premises with drips, a practice prohibited by the hospitals. Some patients for religious reasons refused blood transfusions, and others, especially the Moslem women refused to undress for examination on the grounds that only their husbands were supposed to see them naked.

From interrogations with patients, it was realised that they were given treatment only when they paid for the required materials. Some patients evaded without settling their bills. Some, especially those with venereal diseases, ashamed of their states fled after diagnosis. Other cultural practices required permission to be obtained from some family heads that in turn had to do separate consultations with their "gods" before granting such permission. Some notables (Queens/Princes) were supposed to receive treatment only from particular HCPs, whom, when absent, the patients were doomed to bear their conditions.

Personal observations indicated that most patients were taken care of by elderly people who might not know basic hygiene rules and might have fed patients under unhygienic conditions. This might have impacted on the chain of disease transmission. Discipline and hierarchical respect was not visible in this hospital. This was manifested by the high degree of lateness and absenteeism from work. Patients at times waited for long hours, such that it became difficult to know if work shifts actually 
existed in this hospital sometimes, nurses move in and out of the units and were to be searched during emergencies. Some nurses were in assorted attire and could be seen drinking alcohol at work. Nurses always had consignments of drugs they sold to patients. The origin and quality of the drugs were unknown as they were not checked. The operation room and its windows, at times could be seen open all day long, and workers could also be seen with theatre gowns out of the theatre, at times even eating. The DDH had been witnessing a crisis in terms of patient intake which had been on a downward trend. After interrogations, patients complained of waiting for long hours for doctors who on some occasions did not come. They also complained of rudeness by HCPs, poor toilet facilities, dirty wards, uncomfortable beds with torn mattresses and extortion of money by some HCPs before rendering proper care. They proposed the putting in place of surveillance teams to instill discipline in HCPs, reduce the prices of treatment procedures to affordable rates, recruit cleaners and renovate the hospital infrastructure. All these proposals were taken and lots of positive changes can be seen at the various institutions with the beautification of the exterior of the hospital; landscaped with an array of lawns, hedges and drives well carved out, flowers blooming on flower beds. The population is currently highly motivated to attend these hospitals.

\section{DISCUSSION}

The healthcare industry has many sectors committed to providing healthcare services and products categorized into hospital activities, medicine, dentistry, nursing, pharmacy, scientific or diagnostic laboratories and substances, pathology clinics, residential health facilities, medical equipment, instruments and services, drug manufacturing and delivery, and also other allied health professions such as optometry, medical massage, chiropody, chiropractic, acupuncture, and occupational, music, yoga, physical, respiratory and speech therapy among others (United Nations, 2012; Wikipedia, 2013a). Unfortunately, there is a lack of awareness and demand for many of these services in Dschang, with no ambulatory or residential care. Ambulatory care is primarily out-patient services at facilities such as doctors' offices, out-patient clinics and clinical laboratories, while residential care is concerned with the provision of care such as community care for the elderly, disabled or mental health and substance abuse facilities. The allied health professions involve specialties distinct from dentistry, nursing, medicine and pharmacy (AAHS, 2012). Allied health professionals make up $60 \%$ of the total work force providing a range of diagnostic, technical, therapeutic and direct patient care and support services that are critical to the other health professionals they work with and the patients they serve (AHP, 2012). Today, emphasis on cost-efficient solutions to healthcare delivery warrant an expansion of the allied health force which the WHO estimates to be in shortage of about two million worldwide (Wikipedia, 2013c). It is worth considering the roles of medical secretaries, receptionists, epidemiologists, and also telephone and computerized appointments for patients, which will also warrant an adequate number of consulting personnel to be available.

Access to healthcare in Cameroon is largely contingent upon socio-economic status. In the present study, many patients left against medical advice. General economic hardship and high health care costs contributed to this phenomenon. While government funding is dwindling down, the cost of hospital procedures and medication is rather increasing such that the average and poor Cameroonians find it difficult to meet up with such costs. Thus, the increasing need for the government to increase funding to the health care sector as well as hospital heads to exploit avenues for self-funding that will 
reduce costs. Literature indicates that in some low income countries, coverage of health services is very low among the below the poverty line (Lyengar and Dholakia, 2012). Thus, health systems are under pressure to provide more cost-effective, culturallysensitive, patient involving and sustainable health systems for all citizens (Kuhlmann and Annandale, 2012).

The lack of adequate space for records, lack of comprehension on the importance of the exercise, and lack of medical secretaries and computers in hospitals; contributed to poor data management in the three hospitals. However, the importance of information technology will only be felt if enough expertise can be sought. Without records, there will be no epidemiological data. Generally, in Cameroon, there is no formal surveillance system for community and healthcareassociated infections and no feedback. It can be argued that the absence of infection control programs in most Cameroon hospitals is due to the lack of resources. Human resources in particular are so limited that infection surveillance, prevention and control are a luxury. Data on community and healthcareassociated infections should be documented to raise awareness. Hospitals should put in place infection control teams which should be given the training and support they need. The importance of adequate clinical documentation and records keeping has been reported elsewhere (Adeleke et al., 2012). Outside this study sub-region, informatics has been reported to facilitate healthcare in women (Tundia et al., 2012).

Practices which hindered patient care or enabled, precipitated, reinforced or predisposed to disease transmission were rampant in the study institutions. Because of the non-application of aseptic procedures such as the disinfection of patient's beds before installing new arrivals, skin infections were anticipated. Respiratory tract infections were inevitable due to dirty and dusty environments. Sexually transmitted infections could also be problematic because of poor lavatory systems, contaminated gynaecological equipment and use of contaminated water to wash the genitalia. Practices like sleeping and eating with patients should be abolished through the institution of sanctions to defaulters. The common use of care materials like stool docks by patients must be discouraged. Authorities should endeavour to create adequate space between patient's beds to avoid cross infections; and also create ICUs to harbour critical cases.

Since water was not always available in some of the hospitals (DDH and $\mathrm{AH}$ ), untreated well and spring water was commonly used by patients which could lend them to gastrointestinal infections. Although the water can be treated by boiling or the use of sodium hypochlorite or chloramines to meet acceptable standards, reminders are needed. Hospitals should emulate the HSVP that had an autonomous source of water. In order to improve on hygienic conditions and patients health in the hospitals, it is important for each hospital to set up its own kitchen, so as to control food served to patients, because food sold by vendors was often exposed to flies, dust particles, the wind and rain. Canteens will also prevent movement of staff out of hospital premises. More still, the provision of basic items in canteens (case of the HSVP) contributes in keeping personnel in the hospital. Common infections such as surgical, upper respiratory and gastrointestinal infections are linked to patient feeding, hygiene and the environment. Poor hygiene and sanitation, and contaminated food and water, can cause infection. HCPs should endeavour to monitor the type of food, water and the manner in which these are given to patients. Caretakers should also be educated on clean habits vis-à-vis patient care. The practice of handshaking in hospital should be discouraged since soiled hands lead to the spread of pathogens through handshakes. HCPs serve as reservoirs of infection (FusiNgwa et al., 2007). To avoid cross 
contamination in hospital, HCPs should be given appropriate vaccines. Hospital heads therefore, should ensure vaccines are sent regularly from appropriate headquarters for periodic administration. Adequate care materials and protective apparels especially in the mortuary should be supplied. Patients may die of infectious diseases easily transmissible to the attendant if he is not well protected. A general look at the inhabitants of Dschang gives an impression that personal hygiene is not given much importance. The general state of patients in hospitals was sometimes deplorable, with dirty dresses and overgrown hair. HCPs and caretakers should see to it that patients are cleaned every day. Patients must also endeavour to get first-hand information on health tips from HCPs who should be ready to give this information. The introduction of healthcare assistants will be very useful here. Thankfully, pipe-borne water and canteens can be witnessed in the hospitals day.

Inadvertent exposures to environmental pathogens can result to adverse patient outcomes and cause illness even among HCPs. Thus, thorough environmental sanitation, and appropriate maintenance of medical equipment must be applied. The engagement of cleaners especially in the DDH where not even a single was seen was important and this had been effected from May 2009. In the cases of the $\mathrm{AH}$ and HSVP, adequate numbers should be recruited to avoid over working those in place. The hospitals should be cleaned daily not leaving out weekends as in the AH. Waste should be separated and treated before discarding so that it might not constitute a health hazard to the public. The hospital environment including lawns, wards and walls should be cleaned twice a day i.e. in the morning and late afternoons when patients and visitors must have littered the environment. In the DDH, materials for patient care were not always sterilized when heaters broke down and personnel had to make do with what they had. This might have had a negative impact on the large numbers of probationers streaming into this hospital as they might adopt the same practice elsewhere. Actually, irregular sterilization, and disinfection of contaminated items, and lack of sterilization equipment in some hospitals are factors related to infections.

A major problem facing the whole world today is the development of antimicrobial resistance among clinically important species. Antibiotics in the formulary of any health institution should be tested against pathogens to determine their usefulness in therapy and their resistance patterns. Over-the-counter drugs should be controlled, quack practitioners eliminated from healthcare and illegal institutions dismantled. HCPs should pay prime attention to patient medication and make sure they are taken at regular intervals.

Absenteeism from work, lateness, rudeness and selling of drugs by HCPs must be halted and culprits sanctioned. The $\mathrm{AH}$ and the HSVP being mission hospitals were based on strict moral and ethical practices. Therefore personnel heads in public hospitals must have to go extra miles to instil discipline and hard work on their subordinates. The DDH is the highest state institution in the Menoua Division, and thus, warrants the presence of a doctor for 24 hours. Finally, refresher courses should be organized to update HCPs on the recent healthcare techniques.

In the face of global economic slump, scaling up of services at district levels is mandatory to ensure equitable access to health services in Cameroon. If the rural poor communities at districts cannot afford basic healthcare services, then they cannot travel to the regional or urban centres for specialized care or essential laboratory tests. The government and the Dschang municipality health district have to subsidize care costs for the residents especially as social or private health insurance schemes cannot be paid for, and there are no charities to donate, healthcare expenses being generally borne privately. There are generally five primary methods of funding health care systems: general taxation 
to the state, county or municipality; social health insurance; voluntary or private health insurance; out of pocket payments and donations to health charities (WHO, 2006). Hospitals must appreciate the enormous costs associated with inadequate care delivery and prioritize optimum care for all to minimize costs. The success of any infection control program requires a well-equipped laboratory to generate high quality data that are timely and accessible. A computerized system will enable more effective and more vigorous surveillance and reporting. Of course comprehensive infection rates will be obtained only if bacterial, viral, fungal, parasitic and other infections are summarily evaluated. Barrier precautions and rigorous nursing care needed to be instituted to substantially reduce infection risks. Sound hospital hygiene and that of the greater environment of the hospital, and judicious use of antibiotics have been instituted. This study provided awareness and the necessary stimulus for the institution of change.

\section{ACKNOWLEDGEMENTS}

Special thanks go to the Medical Heads, Administrators, General Supervisors, Nurse Heads, and the entire personnel and patients of the DDH, AH and HSVP for their cooperation.

\section{REFERENCES}

Adeleke IT, Adekanye AO, Onawola KA, Okuku AG, Adefemi SA, Erinle SA, Shehu AA, Yahaya OE, Adebisi AA, James JA, Abdulghaney OO, Ogundiran LM, Jibril AD, Atakere ME, Achinbee M, Abodunrin OA, Hassan MW. 2012. Data quality assessment in healthcare: a 365day chart review of inpatients' health records at a Nigerian tertiary hospital. $J$. Am. Med. Inform. Assoc., 19(6): 10391042.

AAHS (Association of Allied Health Schools). 2012. Definition of Allied
Health Professionals. Asahp.org Retrieved 2012-03-06.

Braithwaite J, Westbrook M, Nugus P, Greenfield D, Travaglia J, Runciman W, Foxwell AR, Boyce RA, Devinney T and Westbrook J. 2013. Continuing differences between health professions' attitudes: the saga of accomplishing systems-wide interprofessionalism. International Journal for Quality in Health Care, 25(1): 8-15.

Evans R, McGovern R, Birch J, NewburyBirch D. 2013. Which extended paramedic skills are making an impact in emergency care and can be related to the UK paramedic system? A systematic review of the literature. Emerg. Med. J. doi:10.1136/emermed-2012-202129 R. Accessed May 10, 2013.

Fusi-Ngwa KCN, Egri-Okaji MTC, Odugbemi T, Iroha E. 2007. A study on pediatric nosocomial methicillin-resistant Staphylococcus aureus in Lagos, Nigeria. Int. J. Biol. Chem. Sci., 1(1): 54-60.

Gomez-Batiste X, Stjernsward J, Espinosa J, Martinez-Munoz M, Trelis J, Constante C. 2013. How to design and implement palliative care public health programmes: foundation measures. An operational paper by the WHO Collaborating Centre for Public Health Palliative Care Programmes at the Catalan Institute of Oncology. BMJ Support Palliat. Care, 3: $18-25$.

Girot E. 2013. Shaping clinical academic careers for nurses and allied health professionals: the role of the educator. Journal of Research in Nursing, 18: 5164.

Kuhlmann E, Annandale E. 2012. Researching transformations in healthcare services and policy in international perspectives: An introduction. Current Sociology, 60(4): 401-444.

Lyengar S, Dholakia RH. 2012. Access of the rural poor to primary healthcare in India. 
Review of Market Integration, 4(1): 71109.

Mpoame M, Essomba L. 2000. Essai de traitement contre des parasitoses gastrointestinales du poulet avec des decoctions aqueuses de graines de papaya (Carica papaya). Rev. Elev. Med. Vet. Pays. Trop., 53(1): 23-25.

Tundia NL, Kelton CML, Cavanaugh TM, Guo JJ, Hanseman DJ, Heaton PC. 2012. The effect of electronic medical record system sophistication on preventive healthcare for women. J. Am. Med. Inform. Assoc., 20(2): 268-276.

United Nations. 2012. International Standard Industrial Classification of all Economic Activities, Rev.3 New York http://unstats.un.org/unsd/cr/registry/regc st.asp?cl=2. Accessed September 15, 2012.

AHP (Allied Health Professions). 2012. Advancing the Allied Health Professions Futurehealth.ucsf.edu. http://www.future health.ucsf.edu/Public/Center-Research/ Home.aspx?pid=88 Retrieved 2012-03-
06. University of California, San Francisco

WHO (World Health Organization). 2006. "Regional Overview of Social Health Insurance in South East Asia" and "Overview of healthcare Financing". Retrieved August 18, 2006.http:// wwwsearo.whoint/en/section1243/section 1382/section1731.htm

WHO (World Health Organization). 2012. Health Systems Geneva, WHO. http://www.who.int/topics/health_systems /en/.

Wikipedia. 2013a. Category: Healthcare occupations. en.wikipedia.org/wiki/ category: Healthcare_occupations. March 13, 2013. Accessed May 10, 2013.

Wikipedia. 2013b. Healthcare, en.wikipedia. org/wiki/Health_care, May 1, 2013. Accessed May 10, 2013.

Wikipedia. 2013c. Allied Health Professions. en.wikipedia.org/wiki/Allied_health_prof essions, May 1, 2013. Accessed May 10, 2013. 